\title{
Liutprand Kremonski, Antapodosis 6: Podoba Bizanca na latinskem Zahodu desetega stoletja
}

\section{Prevedel Kajetan Škraban}

Liutprand Kremonski je bil škof, diplomat in zgodovinar langobardskega porekla, ki je deloval v sredini 10. stoletja. Njegova zgodovinopisna dela Antapodosis, Relatio de legatione Constantinopolitana in Historia Ottonis so nadvse pomembna za poznavanje politične zgodovine 10. stoletja, zlasti za dogajanje na Apeninskem polotoku. Hkrati pa velja tudi obratno: literarna vrednost njegovih del $\mathrm{v}$ veliki meri izhaja iz pogosto duhovite, mestoma pa tudi izrecno napadalne kritike političnih nasprotnikov in nekdanjih zaveznikov.

Nekaj zgodovinskega ozadja: Berengar, ivrejski mejni grof, pod katerim je v začetku svoje kariere služil Liutprand, je leta 945 premagal italijanskega kralja Hugona Arleškega, ki se je umaknil v izgnanstvo, nadomestil pa ga je njegov sin Lotar, čeprav je de facto, kakor poroča Liutprand v spodnjem odlomku, zavladal Berengar. Ko je čez nekaj let Lotar umrl, najbrž nasilne smrti, je želel Berengar Lotarjevo vdovo Adelajdo poročiti s svojim sinom Adalbertom. Adelajda je poroko zavrnila in si prislužila nekakšen pripor, iz katerega jo je leta 951 "rešil« Oton, tedaj še nemški kralj, s čimer se je nazadnje le neposredno vpletel v italijansko politiko. Ko je leta 96o Berengar napadel še Papeško državo, se ji v bran postavi tudi Oton, s čimer je položil temelje za cesarsko kronanje leta 962, ki pomeni nastanek novega »rimskega cesarstva«.

Liutprand že pred tem stopi v njegovo službo in Antapodosis (Povračilo ali Maščevanje) napiše kot obračun s svojim nekdanjim gospodom. Šesta, zadnja in najkrajša knjiga tega dela, vsebuje opis diplomatske poti v Konstantinopel, ki jo je opravil v Berengarjevem imenu. Leta 949 se je namreč $\mathrm{v}$ ne povsem pojasnjenem kontekstu 
odpravil na bizantinski dvor Konstantina viI. Porfirogeneta. Mesto ga navduši: $\mathrm{z}$ najbolj izbranimi besedami opisuje razkošje, dvorno bogastvo in samega cesarja Konstantina. Morda najlepši odlomek, ki opisuje tehnološko napreden avtomat, broneno drevo, na katerem ščebetajo mehanske ptice, pa si je pot utrl celo v moderno poezijo. William Butler Yeats v svoji nekoliko kavafisovski pesmi pravi takole:
Onkraj narave si ne bom nikdar
podob naravnega sveta privzel,
le takšno, kot jo skuje Grk, zlatar,
iz tankih ploščic in prevlek;
da ne zadrema kinkajoč vladar;
mogoče bom na zlati veji pel
gospodi iz Bizanca na uho
o vsem, kar je bilo, kar je in bo. ${ }^{1}$

Povsem drugačno izkušnjo je imel Liutprand na svoji drugi poti, na katero ga je leta 968 poslal njegov novi gospod, Oton I., prvi cesar Svetega rimskega cesarstva. Šlo je za pomembno diplomatsko misijo, saj je imel Liutprand nalogo pridobiti Ano Porfirogeneto za ženo prestolonaslednika Otona II. Nikefor Fokas, tedanji bizantinski cesar, ki je s svojim samozavestnim vojskovanjem močno utrdil državo, Otonovega predloga ni sprejel ugodno: bizantinsko cesarstvo si je vlogo naslednika rimskega cesarstva prisvajalo mnogo dlje in tudi bolj upravičeno kakor novonastalo cesarstvo pod Otonom, zato se mu je zdel Otonov predlog žaljiv. Prav spor o nazivih, ki ga opisuje Liutprand v Poročilu o odpravi $v$ Konstantinopel (Relatio de legatione Constantinopolitana) dobro pokaže mehanizme nasledstvene identifikacije, ki so zaznamovali diplomatske stike med cesarstvoma. Poleg tega pa je nadvse učinkovito literarno besedilo, ki bizantinski dvor prikaže v povem drugačni luči kakor Antapodosis. Liutprand kara vse od "vulgarnih navad « in »ukazovalnih evnuhov« do »ogabnega « smolnatega vina in Nikeforove "pigmejske postave«. Odprava je propadla in Oton II. se je slednjič poročil s Teofano, manj pomembno plemkinjo.

Liutprand je zaradi svojega živahnega pripovedovanja, humorja in občasne pikantnosti zagotovo med najzanimivejšimi latinskimi avtorji 1o. stoletja, svoje sodobnike pa je navduševal tudi zaradi eksotike, ki so jo prinašali »bizantinski« deli njegovega opusa. Pa ne le njih: zaradi dveh povsem nasprotnih opisov Konstantinopla in Bizanca je

1 William Butler Yeats, Zbrana poezija 2, prev. Nada Grošelj (Ljubljana: Hiša poezije, 2015), 96. 
kot eden izmed pomembnih členov v izgradnji »imaginarija grštva«, ki je soustvarjal odnose med cesarstvoma in kulturnima ter verskima središčema, postal tudi pogost predmet raziskovanja sodobnih (kulturnih) zgodovinarjev in zgodovinark.

Prevod je nastal po izdaji, ki jo je za Brepols oskrbel Paolo Chiesa, ${ }^{2}$ ter se opira tudi na tistega, ki je nastal za bolj dostopno in komentirano različico za italijansko zbirko Fondazione Lorenzo Valla. ${ }^{3}$

2 Paolo Chiesa, ur., Liudprandi Cremonensis opera omnia (Turnhout: Brepols, 1998).

3 Paolo Chiesa, ur., Liutprando: Antapodosis (Milano: Arnaldo Mondanori Editore / Fondazione Lorenzo Valla, 2015). 


\section{LIUTPRAND KREMONSKI: POVRAČILO 6}

\section{Proemij}

Narava trenutka, v katerem se nahajam, bi prej terjala, da sem pisec tragedij kakor pa zgodovinar, če ne bi moj Gospod pred menoj pogrinjal mize vpričo mojih nasprotnikov. ${ }^{4} \mathrm{Ne}$ morem opisati, koliko neprijetnosti me pretresa na tujem. Zunanjemu človeku bolj pritiče jokati kakor pisati, toda notranjemu, ki ga utrjujejo Apostolovi nasveti, ti napori prinesejo slavo, saj vemo, da stiska rodi potrpljenje, potrpljenje preizkušenost, preizkušenost upanje. Upanje pa ne osramoti, ker je Božja ljubezen izlita v naša srca po Svetem Duhu, ki nam je bil dan..$^{5}$ Naj se torej zunanji človek podredi notranjemu in naj se ne le ne odvrača od svojih nesreč, ampak naj v njih raje najde svoj mir. In ko se bo polotil pisanja in opisoval, kako kolo usode ene povzdigne, spet druge pa zatre, bo pozabil na trenutne neprijetnosti in se celo veselil spremenljivosti ter se tako otresel strahu pred slabim - ki se pravzaprav še zgoditi ne more, če ne poseže vmes ravno smrt ali šibkost udov - ter tako pričakoval le dobro. Če pa se bodo okoliščine spremenile, bodo kvečjemu prinesle rešitev, ki je sedaj ni na obzorju, kar je trenutno nesrečnega, pa bodo pobile. Naj torej začne s pisanjem in doda temu, kar je opisano zgoraj, še teh nekaj resničnih dogodkov, ki sledijo.

\section{O tem, da cesar Konstantin pošlje Berengarju poslanca}

Ko je v provansalskih deželah umrl kralj Hugon, ${ }^{6}$ je Berengarjevo ime zaslovelo v mnogih deželah, zlasti v grških. V resnici je namreč vladal vsej Italiji, medtem ko je kralj Lotar ${ }^{7}$ vladal le po nazivu. Konstantin, ${ }^{8}$ ki je vladal Konstantinoplu, potem ko se je znebil Romana in njegovih sinov, je slišal, da Berengar po svoji moči prekaša Lotarja in je prek nekega Andreja, ki se je po službi, ki jo je opravljal, imenoval »comiscurtis «, ${ }^{9}$ poslal Berengarju pismo, v katerem je pisalo, da bi si močno želel sprejeti njegovega poslanca, ki bi mu lahko ob

Rim 5,3-5.

6 Hugon Provansalski (ali Arleški), kralj Italije v obdobju 926-945.

7 Lotar, Hugonov sin in kralj Italije v obdobju 948-50.

8 Konstantin vis. Porfirogenet, bizantinski cesar makedonske dinastije.

9 Grški naziv (sicer etimološko latinsko-italskega izvora, kakor velik del bizantin-

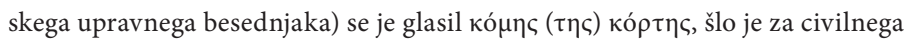
uradnika $\mathrm{z}$ ne povsem pojasnjenimi sodnimi in policijskimi pooblastili. 
vrnitvi prenesel Konstantinovo globoko naklonjenost. Spisal mu je tudi priporočilna pisma za Lotarja, češ da se je Berengar izkazal za njegovega zvestega služabnika, saj je po božji volji njegov skrbnik. Konstantin je namreč za Lotarjevo usodo gojil nemajhno skrb ter je o njem razmišljal naklonjeno zaradi ljubezni do svoje snahe, ki je bila Lotarjeva sestra. ${ }^{10}$

\section{O tem, kako zvijačno je Berengar $v$ Konstantinopel} poslal poslanca, ne da bi ga za to kakorkoli poplačal

Berengar pa, ki je bil do vrha poln zvijač, je premišljeval, koga bi bilo najbolje poslati, ne da bi mu hkrati ponudil sleherno plačilo za tako dolgo pot, ter k sebi poklical mojega očima, pri katerem sem bil tedaj na skrbi. »Kako prav bi mi sedaj prišlo, da bi tvoj pastorek obvladal grščino," mu je dejal. Moj očim mu je odvrnil: "Polovico svojega bogastva bi dal za to. "Oni pa: »Niti stotina ti ni treba zapraviti. Konstantinopelski cesar me v pismu prosi, naj k njemu pošljem svojega poslanca in ne morem se domisliti nikogar, ki bi to mogel storiti bolje zaradi svoje umerjenosti duha ali primerneje zaradi zgovornosti. Odveč bi ti bilo praviti, s kakšno lahkoto bo požiral grško učenost, ko je že v mladih letih goltal latinsko.« Mojega očima je to navdalo $\mathrm{z}$ upanjem in nemudoma mi je pokril vse stroške ter me poslal v Konstantinopel z množico darov.

\section{Kdaj je poslanec odšel iz Pavie in kdaj je prispel $v$ Konstantinopel}

Ob avgustovih kalendah ${ }^{11}$ sem zapustil Pavio in po tridnevnem potovanju po reki Pad prispel v Benetke. Tam sem srečal evnuha Salomona, grškega poslanca koitonita, ${ }^{12}$ ki se je vračal s poti v Španijo in Saško ter nameraval odpotovati v Konstantinopel. Ob sebi je imel Liutefreda, nadvse bogatega trgovca iz Mainza in poslanca mojega gospoda, tedaj kralja in danes cesarja, opremljenega z mnogimi darovi. Osmi dan pred septembrskimi kalendami ${ }^{13}$ smo odpluli iz Benetk ter prispeli

10 Gre za Berto oziroma Evdokijo, kot je bila imenovana na bizantinskem dvoru, ki je bila zaročena s Konstantinovim sinom Romanom.

11 Tj. 1. 8.

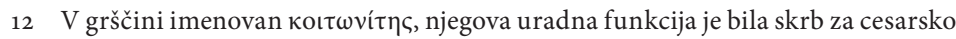

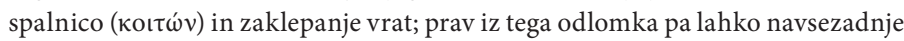
sklepamo, da se je dejanska vloga tega uradnika od izvorne že precej odcepila.

13 Tj. 25. 8. 
v Konstantinopel petnajsti dan pred oktobrskimi kalendami; ${ }^{14}$ in ne bi bilo napak opisati, kako izjemno in čudovito so nas tam sprejeli.

\section{O čudoviti sprejemnici, ki jo imenujejo Magnaura, in o sprejemu poslanca}

V Konstantinoplu je poleg cesarske palače sprejemna dvorana čudovitih razsežnosti, ki jo Grki, če namesto digame postavim u, imenujejo Magnaura, ${ }^{15}$ torej $»$ magna aura ${ }^{16}{ }^{16}$ Konstantin je ukazal pripraviti to dvorano tako za špansko delegacijo, ki je prišla kmalu za tem, kot za naju z Liutefredom. Pred cesarjevim prestolom je stalo nekakšno broneno, a pozlačeno drevo, njegove veje pa so bile polne raznolikih, prav tako bronastih, a pozlačenih ptic, ki so glede na svojo vrsto spuščale različne ptičje glasove. ${ }^{17}$ Cesarjev prestol je bil sestavljen tako umetelno, da se je zdaj zdel nizek, takoj zatem nekoliko višji, kmalu pa zelo visok, varovali pa so ga neznansko veliki levi, za katere je težko reči, ali so bili iz lesa ali brona, prav gotovo pa so bili prekriti z zlatom ter so s svojimi repi udarjali ob tla, iz odprtih ust, $\mathrm{v}$ katerih so se premikali jeziki, pa se jim je izvijalo rjovenje. $\mathrm{V}$ to palačo sta me torej, nameščenega na svoja pleča, pred cesarja odnesla dva evnuha. Ko so ob mojem prihodu zarjoveli levi ter glede na svojo vrsto zaščebetale ptice, me ni to prav nič navdalo ne s strahom ne z občudovanjem, saj so me o tem podučili tisti, ki so takšna čudesa že poznali. Ko sem se v poklon cesarju trikrat priklonil in dvignil glavo, sem cesarja, ki sem ga prej videl sedeti le malo vzdignjenega nad tlemi, sedaj zagledal, kako je v drugih oblačilih sedel skoraj tik pod stropom. Kako se je to zgodilo, nisem mogel ugotoviti, razen če

14 Tj. 17. 9.

15 Poleg Velike palače je stala tudi Magnaura, najbrž prezidana senatna stavba. $\mathrm{V}$ njej so v času makedonske dinastije, najbrž pa tudi kasneje, sprejemali tuje poslance nekako tako, kot to opisuje Liutprand.

$16 \mathrm{Tj}$. »velik piš«, v resnici ime najbrž izhaja iz »magna aula«, tj. »velika sprejemnica«. Liutprand nas s svojo jezikoslovno opombo najbrž opominja, da je bil diftong [au], kot ostali diftongi, v njegovem času že dolgo monoftongiziran, saj se je $v$ izgovarjal priporniško oziroma, kot se izrazi Liutprand, kakor F (ki ga imenuje digama).

17 Iznajdbe povsem enake vrste so poznali v tudi Bagdadu, tedaj glavnem mestu Abasidskega kalifata. Obstajajo tudi poročila bizantinskih poslancev na bagdadskem dvoru, ki poročajo o pozlačenih drevesih in mehanskih pticah. Danes se domneva, da so jih razvili bagdadski učenjaki ob pomoči prevodov del, ki so jih napisali antični mehaniki, kakršen je bil Heron Aleksandrijski. 
ga niso tja dvignili s škripcem, s kakršnim dvignejo klade za prešo. Z menoj ni govoril neposredno, saj bi - tudi če bi hotel - to storil le stežka zaradi velike razdalje, ki naju je ločevala, zato je z menoj govoril prek logoteta ${ }^{18}$ in me povprašal po Berengarjevem življenju in zdravju. Ko sem mu odgovoril na postavljena vprašanja, mi je logotet pomignil in tako sem zapustil palačo ter se umaknil v domovanje, ki so ga uredili zame.

VI O darovih, ki jih je moral Berengarjev poslanik cesarju pokloniti iz svojega žepa v imenu Berengarja, saj ta ni poslal ničesar

A naj mi bo dovoljeno opomniti na to, kar sem potem storil za Berengarja, da se bo vedelo, kakšno naklonjenost sem gojil do njega in kakšno povračilo sem nato dobil od njega za vse dobro, kar sem storil zanj. Španski poslanci in že omenjeni Liutefred, poslanec mojega današnjega gospoda in tedanjega kralja Otona, so v imenu svojih gospodov cesarju Konstantinu prinesli mnogo daril. Jaz pa v Berengarjevem imenu nisem prinesel ničesar razen pisma, pa še to je bilo polno laži. Močno me je skrbelo, da se ne bi osramotil, in veliko sem premišljeval, kaj naj glede tega storim. Ko sem se tako potil od skrbi ter kolebal, mi je prišlo na misel, da bi darove za cesarja, ki sem jih prinesel v lastnem imenu, predstavil kakor Berengarjeve in ta majhen dar, kolikor bi se pač dalo, okrasil z besedami. Poklonil sem mu torej devet poprsnih ščitov najboljše kakovosti, sedem ščitov z zlatimi bulami, dve srebrni, a pozlačeni čaši, nato pa meče, kopja, bodala, pa še štiri sužnje karzimasije, ki so bili cesarju izmed vsega naštetega najdražji. Karzimasije namreč Grki imenujejo skopljene dečke, ki jim odstranijo testise in ud. To zaradi zaslužka, ki ga iz tega iztržijo, pogosto počno trgovci iz Verduna ter dečke nato izvažajo v Španijo.

VII O tem, da je cesar Berengarjevega poslanca povabil $k$ svoji mizi

Po vsem tem so minili trije dnevi, ko me je cesar odredil poklicati v palačo. Z menoj je tokrat govoril osebno ter me povabil na gostijo, po obedu pa obdaroval mene in moje spremstvo. Ker se ravno ponuja priložnost, menim, da velja pisati, ne pa molčati o tem, kakšna je bila miza, zlasti na praznične dni, in kakšne igre so se pred mizo odvijale. 
Nekoliko severneje od hipodroma se nahaja izredno visoka in lepa palača, ki jo imenujejo Dekaennea akkoubita. Ime ni takšno zaradi same stavbe, ampak ima očiten razlog: v grščini namreč deka pomeni "deset«, ennea pa »devet", akkoubita pa prihaja iz besede cubare, torej pomeni zleknjen, naslonjen. Ime torej izhaja iz tega, da na dan, ko je bil Kristus rojen po mesu, postavijo v to palačo devetnajst miz, na katerih cesar in njegovi gostje ne jedo sede kakor na druge dni, ampak zleknjeni, ter ne obedujejo s srebrnih, ampak z zlatih posod. Po obedu pa $\mathrm{v}$ treh zlatih posodah prinesejo sadje, vendar zaradi neznanske teže tega ne storijo človeške roke, ampak ga morajo pripeljati na vozičkih, prekritih s škrlatom. Dve izmed teh posod nato položijo na mizo takole: skozi luknjo v stropu so napeljane tri vrvi, obrobljene $s$ pozlačenim usnjem, $s$ katerih visijo zlati obroči. Te potisnejo skozi ročaje, ki molijo iz posod, nato pa štirje ali še več mož s premičnim škripcem, ki visi izpod stropa, dvigne ter nato spusti posodi na mizo oziroma z nje. Ne bom opisoval vseh iger, ki sem jih tam spremljal, saj je takšno pisanje prezamudno. Toda ne bo odveč, če opišem eno zares izredno.

\section{IX $O$ čudoviti predstavi, ki se je odvijala med večerjo}

Vstopil je neki človek, ki je nosil na čelu, ne da bi si pri tem pomagal z rokami, štiriindvajset ali še nekaj več pedi dolg kos lesa, ki je imel en komolec pod vrhom pritrjeno dva komolca dolgo prečno os. Vstopila sta tudi dva dečka, ki sta bila povsem gola, razen v ledja, ki sta jih imela prepasana, ter splezala na drog ter na njem izvajala akrobacije, nato pa se po njem spustila z glavo navzdol, ne da bi ga premaknila za eno samo ped, tako da se je zdelo, kot da je drog pričvrščen v zemljo. Prvi se je nato spustil, drugi pa ostal gori in izvajal takšne norčije, da me je od občudovanja pustil povsem brez besed. Dokler sta bila na drogu oba, se je zdelo vse skupaj še nekako možno, saj sta, čeprav na povsem neverjeten način, s svojo podobno težo držala v ravnovesju drog, po katerem sta plezala. Ko pa je na drogu ostal samo še eden, me je njegova sposobnost, da je vzdrževal ravnotežje, hkrati izvajal akrobacije in se spustil $\mathrm{z}$ droga živ in zdrav, tako očarala, da moje začudenje ni ušlo niti samemu cesarju. Tako je poklical tolmača in me vprašal, kaj me je bolj očaralo - deček, ki se je gibal s takšnim občutkom za ravnotežje, da se leseni drog ni niti premaknil, ali moški, ki je drog na svojem čelu nosil tako trdno, da ga niso mogli niti za ped premakniti ne teža dečkov ne njune akrobacije. Ko sem odgovoril, da 
težko rečem, kaj od tega se mi je zdelo thaumastoteron, ${ }^{19}$ je izbruhnil v krohot ter dejal, da se tudi sam podobno težko odloči.

$<X \ldots>$

Toda menim, da ne morem zamolčati še ene čudovite stvari, ki sem jo videl v tej palači. V tednu pred praznikom, ki ga imenujejo baiophoros, mi pa cvetna nedelja, cesar v zlatu pokloni vojakom in različnim veljakom ter uradnikom določene darove, kolikor pač vsakomur pripada glede na položaj. Ker je želel, da sem ob tem obdarovanju navzoč, me je dal poklicati. Bilo je takole. Postavili so mizo, ki je v dolžino merila deset komolcev, $v$ širino pa štiri, in je bila prekrita $z$ vrečkami, na katerih je posamič pisalo, kolikšne zneske vsebujejo, glede na to, koliko je komu pripadalo. Uradniki in vojaki pa pred cesarja niso stopali vsi hkrati, ampak ko jih je poklical glasnik, ki je na glas prebiral na vrečah napisana imena v skladu z dostojanstvom, ki je pripadlo posameznim nazivom. Izmed teh je bil prvi poklican rektor palač, ki je dobil toliko novcev, da denarja ni mogel vzeti z rokami, ampak si ga je oprtal na ramena, zavitega v štiri skaramangije. ${ }^{20}$ Nato sta bila poklicana o domesticos tis ascalonas in o delongaris tis ploos, ${ }^{21}$ izmed katerih je prvi poveljnik kopenske vojske, drugi pa mornarice. Njima je bila namenjena enaka vsota, saj sta tudi po nazivu enaka, denarja in vojaških plaščev, ki sta jih prejela, pa zaradi količine nista odnesla na plečih, ampak z veliko truda s pomočjo drugih ljudi. Nato je na vrsto prišlo štiriindvajset magistroi, vsakemu izmed njih je cesar poklonil štiriindvajset liber zlata in dva vojaška plašča. Njim so sledili patrikioi, ki so dobili dvanajst liber zlatnikov in po en vojaški plašč, vendar ne vem, koliko je bilo teh patricijev in tako tudi ne, koliko liber zlata je bilo razdeljenih. Nato so poklicali nepregledno množico, ki so jo sestavljali protospatharioi, spatharioi, spatharokandidatoi, koitonites, manklabitai in protokaraboi, ${ }^{22}$ ki so v skladu s svojim nazivom dobili po sedem, šest, pet, štiri, tri, dve ali eno libro zlatnikov. A ne misli si, da je bila vsa ceremonija izvedena v enem samem dnevu: začela se je v četrtek in trajala od prve do četrte ure, nadaljevala v petek in končala

19 Gr. »najčudovitejše«. Liutprand skuša latinske bralce 10. stoletja, ki grščine nikakor niso bili vešči, mestoma očarati s svojim znanjem tega jezika.

20 Nadvse dragoceni plašči, eden najbolj luksuznih izdelkov, ki so jih izdelovali Bizantinci.

21 Med nazivi, ki sledijo, nekateri sploh niso ustrezno zgodovinsko pojasnjeni, večinoma gre za vojaške nazive.

22 Večinoma visoki civilni uradniki. 
v soboto, vsaj kar se tiče cesarja. Tistim namreč, ki so dobili manj kot libro, tega zneska ni podelil sam cesar, ampak parakoimomenos, ${ }^{23}$ in to je trajalo še ves teden pred veliko nočjo.

Ker sem podeljevanju denarja prisostvoval in ga spremljal z velikim občudovanjem, me je cesar prek logoteta vprašal, ali mi stvar ugaja. Odgovoril sem mu: »Ugajalo bi mi, če bi tudi meni prineslo kakšno korist; kakor bi tudi bogataš, ki trpi v plamenu in vidi Lazarja v njegovem blaženem počitku, $v$ tem užival le, če bi mu to kako koristilo. ${ }^{24}$ Njemu se to ni zgodilo - kako, mi povej, naj bi torej to ugajalo meni?« Cesar se je zasmejal, malo tudi od sramu, nato pa mi pomignil, češ, naj pristopim; rade volje mi je poklonil velik plašč in libro zlata, jaz pa sem ju še raje sprejel.

23 Nekakšni komorniki, večinoma evnuhi, ki so bili med najpomembnejšimi dvornimi uradniki.

24 Lk 16,23-25. 